2

3 Abstract:

4 Purpose - This study is a systematic literature review of crowdsourcing that aims to present the research evidence so far regarding the extent to which it can contribute to organisational performance and produce innovations and provide insights on how organisations can operationalise it successfully.

Design/methodology/approach - The systematic literature review revolved around a text mining methodology analysing 106 papers.

Findings - The themes identified are performance, innovation, operational aspects and motivations. The review revealed a few potential directions for future research in each of the themes considered.

Originality - This study employed Quantitative Content Analysis in order to identify the main research themes with higher reliability and validity. It is also the first review on crowdsourcing that incorporates the relevant literature on crowdfunding as a value-creation tool.

Research/Practical implications - This study helps researchers to consider the recent themes on crowdsourcing and identify potential areas for research. At the same time, it provides practitioners with an understanding of the usefulness and process of crowdsourcing and insights on what the critical elements are in order to organise a successful crowdsourcing project.

Keywords crowdsourcing, crowdfunding, crowd venturing, systematic literature review, innovation, new product development, platforms, projects, collective intelligence, wisdom of the crowd

Paper Type Literature Review

\title{
Crowdsourcing: a systematic review of the literature using text mining
}




\section{Introduction}

Crowdsourcing has recently received increasing attention from organisations and academics due to the opportunities it offers to firms for development and growth. These opportunities lie in easy access to distant human, social and network capital that can lead to value-creation and efficient solutions. In today's rapidly changing environment, characterised by short product lifecycles and high competition, it is challenging for ventures to survive and sustain competitive advantage. Therefore, they try to find efficient ways for problem-solving and acquiring resources in order to produce innovations and economic value. Access to multiple resources is necessary both for nascent and mature firms. For young ventures, the time between their conception and the revenue creation is critical and building a resource network, which can accelerate this process is essential (Stayton \& Mangematin, 2019). However, such access can also be significant even for mature ventures, which need to sustain or expand their market share. In such a context, crowdsourcing is an attractive proposition as it can enhance resources by opening up organisational boundaries to external actors (Afuah \& Tucci, 2012). (Howe, 2009) was one of the first to describe crowdsourcing as the act of assigning a task that would be traditionally fulfilled by employees of a company to individuals or teams outside of an organisation, i.e. outsourcing, but through an open-call invitation directed to a heterogenous, indistinct and vast pool of people.

The crowdsourcing literature has grown over the years, with a number of reviews aiming to systematically and critically analyse it from different vantage points. For example, the review by (Assis Neto \& Santos, 2018) focused on the quality and workflow control aspects, while the work by (EstellésArolas et al., 2015) suggested a typology. The review by (Hossain \& Kauranen, 2015) primarily focused on the applications and the work by (Ghezzi et al., 2018) approached crowdsourcing as a process. Despite reviews covering a range of topics in this area, their coverage of crowdsourcing skills has been relatively scarce. Crowdfunding in previous reviews of crowdsourcing has either been presented exclusively as a category of crowdsourcing that is used to crowdsource financial value (Assis Neto \& Santos, 2018; Estellés-Arolas et al., 2015) or it has been completely excluded, which is also selfdeclared as a limitation (Ghezzi et al., 2018; Hossain \& Kauranen, 2015). It is broadly agreed that crowdfunding is more than an alternative form of finance, as it offers additional value to the different stakeholders (Alfiero et al., 2014; Gleasure \& Feller, 2016; Mollick \& Robb, 2016; Short et al., 2017). There is also consensus that in the future it will be even more established as a space that bridges the organisation's funding gap, market and knowledge (Alfiero et al., 2014; Gleasure \& Feller, 2016; Julien, 2007; Nucciarelli et al., 2017; Short et al., 2017).

Given the above, there is a need to adopt a wider stance. The objective of this paper is to present a holistic overview of the literature on online crowdsourcing. This is achieved by first highlighting what the evidence is for the value of the crowd as a solution provider and how this value can bring innovation results and increase the performance of a firm. Later, insights are presented regarding operational aspects and the construction and mobilisation of the crowd itself. In addition, the paper aims to illustrate the aforementioned perspective in online crowdfunding as an extended valuecreation ecosystem. Based on this literature review, firms can get a better understanding on how crowdsourcing can be leveraged for organisational purposes. Furthermore, researchers can consider the literature areas and identify potential topics for future research. Last, this paper adopts a systematic approach that is based on a quantitative content analysis, making it possible to shed light on emerging themes with higher reliability and validity (Riffe, 2005; Short et al., 2010).

This study is structured as follows. The next section presents the methodology that was employed to conduct the systematic literature review. The two sections following present the emerging themes derived from quantitative content analysis and the analysis of the research through the main categories identified. The final section concludes with recommendations for future research. 


\section{Methodology}

A research literature review should have four main attributes: being systematic in the way it develops the methodology; being explicit by providing the process in detail; being comprehensive by covering the spectrum of the relevant research; being reproducible by allowing other scholars to understand it and use the same approach (Fink, 2005; Okoli \& Schabram, 2010).

This literature review follows the guidelines recommended by (Tranfield et al., 2003) in the direction of identifying published research work in the areas of crowdfunding and crowdsourcing. It consists of three stages: 1) planning the review 2) conducting the review and 3) reporting and dissemination, which are adopted in this study, as depicted in Figure 1 , and these are discussed more thoroughly in the following part of this section.

\section{Insert Figure 1 here}

\subsection{Planning the review}

During the planning step, an exploration of the subject was undertaken in order to gain a sense of the definitions, the main concepts and perspectives and to acquire a preliminary overview of the area. This was performed through an iterative process and concluded by implementing the subsequent review protocol based on the identified research gaps.

\subsection{Conducting the review}

In order to conduct the review, the tasks included searching the literature, assessing and extracting the most relevant papers and composing the research synthesis (Tranfield et al., 2003). These are outlined below in turn.

Sample selection: The database search, conducted in August 2019, considered the title, abstract, keywords and context of the manuscripts using the terms "crowdfunding" or "crowd funding" or "crowdsourcing" or "crowd sourcing". The criteria of selection included that: a) the language is English, b) the papers are published in peer-reviewed journals and c) the subject areas are limited to Business, Computer Science, Decision Sciences, Psychology and Economics and Social Sciences. The final number of the papers was 1062. The second step was conducted by two reviewers and included two rounds of assessment of papers through reviewing the titles, abstracts and keywords of the papers. This assessment was based on the relevance of the papers to the concept of crowdfunding or crowdsourcing and targeted studies that can make a theoretical contribution. Studies that were completely focused on technical crowdsourcing applications were excluded. This process led to the final number of 106 papers.

Research Synthesis: The synthesis stage is concerned with "summarising, integrating, and, where possible, cumulating the findings of different studies on a topic" (Tranfield et al., 2003). This was performed through the method of Quantitative Content Analysis (QCA), which employs systematic coding techniques in order to classify parts of text and draw inferences about the communication content (Krippendorff, 2004). QCA was utilised through QDA Miner software and its extension WordStat, which have been used successfully for text analysis across different domains of research (Al-Rawi, 2017; Davlembayeva et al., 2019; Hartt, 2018). The main advantage of these tools lies in the fact that they combine a variety of well-established qualitative and quantitative measures, such as in Table I, which allows for the verification and replicability of the process and results. They also accept and relate numerical to categorical data, allowing the creation and configuration of project-based dictionaries and integrating different types of text analysis visualisation that provide a comprehensive system for experimentation, development and finalisation of the analysis (Davlembayeva et al., 2019). The source of this analysis included the titles, abstracts, keywords, author names and all the 
information about the paper's publication. The first step of QCA was content pre-processing and included removal of punctuation marks, symbols and common words, lemmatisation of the words, so as to count as a single word those that have common roots and high-frequency words that were not context related, such as "journal", "paper", "article", "finding", "research", "study", "analysis", "reference", "gap". This technique provided a fast, labour-efficient and accurate analysis of the major themes in the literature, but it does not offer an exhaustive representation of the secondary dimensions in each category. Thus further analysis is relied on combining the results with domain knowledge and the critical judgement of the researchers. The final analysis is presented in the Findings section below.

\subsection{Reporting and dissemination}

The third stage of reporting and dissemination aims to present a summary of the results through descriptive statistics and offer insights into the different themes and perspectives covered in the literature. Figure 2 shows that the major stream of research on crowdsourcing starts in 2008 and demonstrates an extensive growth mainly after 2012. The topic has been approached from various methodological angles, as depicted in Figure 3.

Insert Figure 2 here

Insert Figure 3 here

\section{Findings: Themes on crowdsourcing}

Quantitative Content Analysis was used to identify the most frequent terms that are encountered in the literature. Table I illustrates these terms along with the frequency with which they appear in the documents, the number and percentage of manuscripts in which they appear (No. Cases and \% Cases respectively) and the Term Frequency - Inverse Document Frequency (TF IDF), which is a measure used to identify the words that are most frequent but relevant to the context (Aizawa, 2003). As expected, crowdsourcing and crowdfunding were among the most frequent terms. A surprising finding is that innovation is the first most frequent term after the topic terms, which reflects the high scholarly interest in using crowdsourcing, not as an instrument of execution of simple tasks, but for knowledge and value creation. The term frequency list also reveals the main stakeholders involved. Then, task, process, work, model, project refer to more operational aspects of the crowdsourcing activity, while innovation and product development refer to its objectives. Last, participation appears naturally to be of high frequency, as it is a prerequisite for crowdsourcing activity. Similarly, motivations appear frequently as they are the driving and engaging force to maintain participation.

\section{Insert Table I here}

The dendrogram in Figure 6 shows in a hierarchical way which entities have high correlation between them based on their co-occurrence in research papers. The entities with the closer distance appear first in a cluster. For example, crowdsourcing and crowd are linked, and then this cluster is linked with a sprig with the next closest cluster and so on. 
The last step of the content analysis was to perform a topic extraction (Table II). Cluster analysis made it possible to organise the reporting of the literature into sections with higher validity and representativeness. These topics were thematically grouped further into larger categories, with each reviewed in the section following. For example, platforms, projects and crowd became sections of the category "operational", as all of those describe aspects related to the implementation of crowdsourcing activity. Open innovation and product development were placed under the category "innovation", as they consist of the two innovation applications of crowdsourcing. The cluster of social capital carries a semantic meaning that is cross-category; the social capital as a skill to attract, communicate and collaborate with individuals is an ingredient of successful firms, projects, platforms and crowd participants, and thus it is discussed indirectly in all the sections.

\section{Insert Table II here}

\section{Findings \\ 4.1 Crowdsourcing Performance}

The crowd as a solution provider and the role of the experts: Online crowdsourcing models became popular as the development of ICT empowered the swift communication and mobilisation of a high number of individuals across the globe, introducing higher efficiency in problem-solving. Such efficiency established the term "wisdom of the crowd", a reputation that comes from the performance of the crowd and the related benefits it provides to organisations. Crowds, being negatively characterised through history as non-thinking and easy-to-manipulate masses, started being seen as problem-solvers, innovators and conveyors of intelligence (Wexler, 2011). Performance benefits lie mainly in two dimensions: efficiency in processes and efficiency in quality. Efficiency in processes includes time and cost reduction. Time reductions are due to the fast aggregation of distributed value and the orchestration of simpler decomposed tasks or heterogenous collaboration, in order to achieve more complex goals (Gruner \& Power, 2017; Stol et al., 2019). When it comes to quality efficiency, the wisdom of the crowd is a result of ideas aggregation. Such collective power has the ability to outshine the excellence of an individual performance (Brabham, 2010). The openness of participation and processes in crowdsourcing can result in knowledge-related benefits derived from a higher number of submissions, human intelligence and intuition, access to rare and specialised skills, knowledge diversity from high human diversity, knowledge sharing and verification (Franzoni \& Sauermann, 2014). The wisdom of the crowd also lies in the ability to make successful judgements or evaluations with the crowd norm, counterbalancing outlying fallacies (Hervé \& Schwienbacher, 2018). At the same time, the crowd can support the democratisation of access to services and capital. The contention is that the direct transactions between the two sides of a market helps to supplant the traditional distribution channels and consequently lower the entry barriers for creators and organizations in the market of innovation, labour and investments. For instance, the crowd can provide opportunities in cases that experts would reject (lyer et al., 2015; Sørensen, 2012). Still, several scholars questioned whether the crowd can make valid contributions to innovation-driven and specialised projects, such as co-creating new products or making investment decisions, where traditionally the requirement for expert participation had been considered imperative (Ebel et al., 2016; Hervé \& Schwienbacher, 2018; lyer et al., 2015; Keongtae Kim \& Viswanathan, 2019; Poetz \& Schreier, 2012; Walthoff-Borm et al., 2018; Wang et al., 2019; J. J. Zhu et al., 2017) . Other studies suggest that experts can play the role of "moderator" in order to bear the potential costs, such as task fulfilment uncertainty, lack of experienced perspective and ambiguous credibility (Lüttgens et al., 2014; Muthukumaraswamy, 2010; O'Neil, 2010; Y. Tran et al., 2016; Walthoff-Borm et al., 2018). Such a debate does not necessarily confute the crowd's reputation, because the crowd may also include experts (Brabham, 2012; 
Keongtae Kim \& Viswanathan, 2019). Given the above, the literature supports the complementary nature of expert and crowd collaboration, in such a way that their collective inputs may lead to an extraordinary ferment.

Crowdsourcing skills to improve organisational and market performance: While one consideration is whether the crowd is able to provide substantial value to organisations, a transposed consideration is whether organisations can capitalise this value. By approaching crowdsourcing and crowdfunding as a value-creation tool, scholars have recently started exploring whether organisations can leverage on improving their organisational performance and ultimately their market performance. Concerning the first, there is evidence that companies which have high adaptive capacity are open to information signals from the crowd. As such, they can absorb external information in their knowledge and processes and manage to improve their innovation competences and organisational outputs (Gruner \& Power, 2017; Stanko \& Henard, 2017; Xu et al., 2015). For example, the creation of a community around a product or service can lead to innovation-related benefits (Agrawal et al., 2015; Lehner, 2013; Stanko \& Henard, 2017). This is further reflected in the number of patent applications. Companies that fundraise through equity crowdfunding apply for a significantly higher number of patents compared to those that get funding from traditional institutions (Walthoff-Borm et al., 2018).

Another recent area of research concerns the connection of crowdsourcing and crowdfunding with organisations' market performance, either through sales or capital investments. A crowdsourced product design improves usability and reliability and consequently increases sales (Allen et al., 2018). In addition, products that are marketed as crowdsourced are found to sell more units because they are preferred for being co-created by consumers for the consumers (Nishikawa et al., 2017). There is also evidence that under certain conditions firms that employ crowdsourcing can capture value further, as reflected in their fundraising, investments and future stock market performance (Cappa, Oriani, et al., 2019; Di Pietro et al., 2018a; Hervé \& Schwienbacher, 2018; Stanko \& Henard, 2017; Xu et al., 2015). For example, in the context of crowdfunding, when the crowd is involved in the campaign activities this can help the company to bridge the funding gap and reach its funding goals (Agrawal et al., 2015; Hong et al., 2018; Mollick \& Robb, 2016; Thürridl \& Kamleitner, 2016; Vismara, 2016). Funders that believe in the success of a project or its social cause advocate for it on social media and help to attract more funds (Hong et al., 2018; Kang et al., 2017). In addition, the option of collaboration as a reward for a project's funders is linked with successful campaigns (Thürridl \& Kamleitner, 2016). The effects of crowd involvement in the post-campaign outcome have also received attention recently with contradictory findings. Crowdfunding companies that leverage the crowd knowledge perform better when it comes to future rounds of fundraising. The knowledge acquisition, the trust of crowd investors in the potential of the company and the established demand from the early customers are perceived as innovation signals and act as "collateral" for future investors (Di Pietro et al., 2018a; Hervé \& Schwienbacher, 2018; Mollick, 2016; Roma et al., 2017). Future stock market performance has also been found to be influenced by firms that engage in crowdsourcing as innovation-related activities are perceived as a promising signal by investors (Cappa, Oriani, et al., 2019). At the same time, though, crowdfunding companies that leverage on value-creation are found to show higher post-campaign failure rates, a phenomenon worth studying further (Di Pietro et al., 2018b; WalthoffBorm et al., 2018).

\subsection{Crowd Innovation}

\subsubsection{Open Innovation}

Maximising the knowledge search for increased innovation performance: Crowdsourcing is considered a major instrument for open innovation (Afuah \& Tucci, 2012; Cappa, Oriani, et al., 2019; Lüttgens et al., 2014). How open organisations are to successfully produce innovations is closely related to the degree to which they search for knowledge i.e. open or knowledge search and, more specifically, to the breadth and depth of knowledge search (Terjesen \& Patel, 2017). Crowdsourcing can maximise the breadth and depth of knowledge search as it can extend searching to a theoretically 
"infinite" external space and resources (Afuah \& Tucci, 2012). Depth of knowledge has been found to be linked to market performance and the breadth to radical innovation and product differentiation (Stanko \& Henard, 2017). Crowdsourcing has also been approached as a form of innovation network that performs when three processes are enabled: knowledge mobility, which includes the facilitation of stimuli, information exchange and acquisition; secondly, innovation appropriability, as the ability to capture and distribute value in a fair way; and thirdly, dynamic stability of the innovation network, as an agile and sustainable engagement in innovation activities with strong adaptation to changes and entrance/exit of participants (Dhanaraj \& Parkhe, 2006; Feller et al., 2012).

Innovation enablers in crowdsourcing - crowd competences: A keystone for efficient innovation processes is to attract a big and diverse pool of contributors, as the more the sources, the more and better the concentrated knowledge (Afuah \& Tucci, 2012; Allen et al., 2018; Feller et al., 2012; Hanine \& Steils, 2019; Steils \& Hanine, 2016). High participation can ensure sufficiency of submissions and bring a diversity of skills and backgrounds in order to promote thinking out of the box and the creation of new knowledge (Allen et al., 2018; Feller et al., 2012). In addition to creative thinking, diverse participants enable the efficient execution of tasks (Steils \& Hanine, 2016). A number of studies have identified ways in which organisations can attract participants. An important example of such an approach is to activate the right motivations (Cappa, Rosso, et al., 2019; Ketonen-Oksi et al., 2017; Y. S. Lee et al., 2015). Relevant participations have also been found to further enhance innovation processes and knowledge creation. For this reason firms with strong brands can be more successful in leveraging innovative outcomes, since they can attract relevant participants, already familiar with their activities (Cappa, Oriani, et al., 2019; Feller et al., 2012; Steils \& Hanine, 2016).

Depending on the crowdsourcing objective, the crowd may contribute to the three stages of innovation: idea generation, idea implementation and idea diffusion (Muller et al., 2012; Scholz, 2015). Past research has identified what the required participants' characteristics are and how they are linked to better results in each of the aforementioned stages. The innovation processes and task execution require a great diversity of skills: technical, analytical, communicational and managerial (Steils \& Hanine, 2016). Medium domain relevant skills (Mack \& Landau, 2015) and an educational background that is at least partially related to the project were found in individuals who submit winning ideas, as background relevance helps individuals to have better understanding of the preferred outcome and thus provide more relevant ideas (Boons \& Stam, 2019). Rewards are also

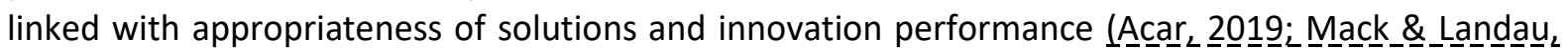
2015). Surprisingly, although creativity is thought of as a seed of innovation, very creative individuals were not found to submit highly innovative ideas nor ideas that are selected by companies to get implemented (Mack \& Landau, 2015; J. J. Zhu et al., 2017). Creativity was only found to be related to a high degree of idea generation (H. Zhu et al., 2014).

Innovation enablers in crowdsourcing - procedural aspects: Procedural aspects have been linked with the facilitation of innovation. An open call with diverse rewards can offer satisfaction to different types of individuals and attract diverse participants (Feller et al., 2012; Saxton et al., 2013). Moreover, the relationship of task description and participants' motivation has been explored. Lengthy descriptions that include more constraints are perceived as a restriction on participation for rewardoriented individuals, but intrinsically-motivated participants are not found to get influenced (Steils \& Hanine, 2019).

After the open call, organisations need to facilitate innovation enablers throughout the crowdsourcing process. Sharing and highlighting information will allow participants to build on previously produced knowledge and perform knowledge combination and integration (Malhotra \& Majchrzak, 2014). Additionally, community identification and social rapport, shared language and vision between the project team and the crowd empower the collaboration and are found to be important in producing product innovations (Eiteneyer et al., 2019; Hanine \& Steils, 2019). Facilitation of trust, justice and fairness in the crowdsourcing processes and fair distribution of ownership IP rights affect the 
willingness to participate and contribute towards the company's financial and reputational goals (Feller et al., 2012; Franke et al., 2013; Hanine \& Steils, 2019; Ketonen-Oksi et al., 2017).

\subsubsection{Product Development}

Crowdsource for product development: Companies many times decide to crowdsource for New Product Development (NPD) (Allen et al., 2018; Elia \& Margherita, 2018; Zahay et al., 2018; H. Zhu et al., 2014). A number of academic papers have dealt with what drives managers to select crowdsourcing for NPD (Allen et al., 2018; Gruner \& Power, 2017; Ketonen-Oksi et al., 2017; Zahay et al., 2018). Innovation-related benefits connected with knowledge production are a core objective (Gruner \& Power, 2017). Another reason is to refine a product in order to increase its perceived usability and meet consumer preferences (Allen et al., 2018; Gruner \& Power, 2017; Nishikawa et al., 2017). Similarly, crowd funders may choose to run crowdfunding campaigns over traditional funding in order to elicit in parallel knowledge about consumer preferences (Nucciarelli et al., 2017; Scholz, 2015). Managerial and organisational factors also affect whether to crowdsource for NPD. Corporate leadership might want to promote more informed decision-making (Zahay et al., 2018). Moreover, the adaptive capability of the organisation influences how open a firm is to adopting new ways of creation and new processes for collaborations and the integration of new knowledge (Gruner \& Power, 2017; Ketonen-Oksi et al., 2017; Zahay et al., 2018).

Different gain in different stages of product development: It is important to understand how beneficial and suitable crowdsourcing is for different stages of NPD. Findings have so far been ambiguous. On the one hand, there is evidence that companies many times crowdsource to find new product ideas (Bayus, 2012; Poetz \& Schreier, 2012; J. J. Zhu et al., 2017). Other studies conclude that companies might prefer first to sketch a prototype and then employ crowdsourcing to deal more efficiently with the increasing technical complexity or commercialisation (Allen et al., 2018; Zahay et al., 2018; H. Zhu et al., 2014). One reason for this may be that crowdsourcing is relatively new for many organisations. In such cases organisations may want to create and test processes in an internal, safer environment and then use them to crowdsource externally (Zahay et al., 2018). In general, a common practice among inexperienced firms is to perform pilot crowdsourcing projects first (Zahay et al., 2018).

Another consideration is whether crowdsourcing is more suitable for front-end innovation or for product refinements at the later stages of testing and commercialisation. Evidence shows that companies that are in later stages of product development can still benefit from radical innovation (Stanko \& Henard, 2017). The value that can be added in each stage of the product development depends on several factors. For example, for certain product features, crowdsourcing can contribute towards improving perceived usability and reliability throughout all the development stages (Allen et al., 2018). Interestingly, perceived usability does not only increase because of actual feature refinements, but also as a result of consumers' assumptions on the value of products that are marketed as "crowdsourced" (Nishikawa et al., 2017).

\subsection{Operational}

\subsubsection{Platforms}

Platforms facilitating value creation as solver brokerages: Online crowdsourcing is carried out by platforms which act as intermediaries between organisations and the crowd. Their characteristics can combine the characteristics of an online marketplace and an online community to varying extents (Marjanovic et al., 2012; Zogaj et al., 2014). They can accommodate the participants' listings, realise their agreements, enable incentives, participation and value creation while they obtain commission for their services (Ford et al., 2015; Marjanovic et al., 2012; Taylor \& Joshi, 2019; Zogaj et al., 2014). The extent to which the platforms provide a conducive space for communication within the valuecreation process defines how much platforms shift towards the community side (à Campo et al., 2019). 
Based on the mediating role they take up in the value creation process, there are three categories of crowdsourcing platforms (Kohler, 2015). First, platform integrators, which "buy" value from the crowd and "sell" it to companies, such as platforms that support crowdsourcing contests (Kohler, 2015). Then, product platforms, which resemble online collaborative communities, as open source communities, and aim to call the crowd to work on specific product refinements, and then sell it to the market (Kohler, 2015). Last, multi-sided platforms with which the crowd and the crowdsourcers interact directly (Kohler, 2015). Crowdsourcing platforms have the mission to provide a solver brokerage system built on three pillars: a good network, appropriate knowledge facilitation and partnerships empowerment (Feller et al., 2012; Yuan \& Hsieh, 2018). A good network is necessary to provide organisations with a pool of a high number and high variety of individuals, skills and talents, which are requisites for co-creation (Schmidt \& Jettinghoff, 2016; Yuan \& Hsieh, 2018; Zogaj et al., 2014). When the matching of appropriate actors is secured, knowledge facilitation mechanisms are necessary to ensure a productive crowdsourcing process. This includes all the digital affordances for knowledge management: sharing, organising, evaluating and storing (Yuan \& Hsieh, 2018; Zogaj et al., 2014). Partnership empowerment refers to maintaining participation and engagement to fulfil the process (Yuan \& Hsieh, 2018). There are many factors that can help to build these three pillars. An accommodating platform design is the ground to build on and this translates into several elements. A digital brand name with a clear purpose and good reputation helps to attract relevant stakeholders (à Campo et al., 2019). In addition, user-friendly website design helps to broaden participation by offering an inclusive environment for the less technology-skilled participants (Deng et al., 2016; Niu et al., 2019). A high variety of functions can also enhance the crowdsourcing activity (à Campo et al., 2019; Deng et al., 2016; Kohler, 2018; Niu et al., 2019; Schmidt \& Jettinghoff, 2016; Zogaj et al., 2014).

In addition to efficient performance of the crowdsourcing platforms, these three pillars are also important for their expansion. Network effects bring more participants, contribute to knowledge facilitation and create resilience to deal with fluctuations in the activity of crowd members (Kohler, 2018). Network effects depend on the availability of relevant stakeholders, which determines not only the expansion of platforms, but also the platform creation itself (Dushnitsky et al., 2016). For example, there is a higher probability for a crowdfunding platform to flourish in countries where the market is big and there is entrepreneurial orientation (Dushnitsky et al., 2016).

\subsubsection{Projects}

The practical objectives of crowdsourcing can remain unfulfilled due to problems associated with project design and execution. Thus, attention is needed throughout all the stages of crowdsourcing to planning, open call, running the activity and evaluating the results (Chiu et al., 2014).

Pre-activity decisions on how to crowdsource/on participation and task execution: The decision making for designing a fruitful project is determined by four areas: user participation, the type of the task, process management and the expected outcome (Chiu et al., 2014; Saxton et al., 2013; Ye \& Kankanhalli, 2013). User participation can be in the form of open/closed collaboration or competing challenges (Chiu et al., 2014; Ye \& Kankanhalli, 2013). In open collaboration, the requirements are absent or loose (Chiu et al., 2014; Ye \& Kankanhalli, 2013). This type of participation is more suitable for tasks that are harder to decompose, have less defined goals and accumulation of knowledge through cooperation is an objective (Niu et al., 2019; Ye \& Kankanhalli, 2013). In the closed type of collaboration organisations apply strict criteria or pre-screening of candidates (Chiu et al., 2014; Ye \& Kankanhalli, 2013). Closed collaboration is preferable for problems that need longer time to get solved (Niu et al., 2019; Ye \& Kankanhalli, 2013). Competing challenges, on the other hand, do not promote collaboration and the task has clearly defined requirements and outcomes (Chiu et al., 2014; Ye \& Kankanhalli, 2013). They are most suitable for tasks where the evaluation of submissions is easier and the initiator expects high diversity of solutions (Chiu et al., 2014; Niu et al., 2019; Ye \& Kankanhalli, 2013). After choosing the type of participation, organisations need to select the right model, by taking into account the nature of the expected outcome, whether it is objective (e.g. microtasking) or 
subjective (e.g. idea crowdsourcing), whether the submissions need to be aggregated (e.g. votes) or filtered (e.g. creative solutions), where the crowd will originate from, inside or outside the organisation, the form of co-creation, collaborative or independent, and the IT platform, inhouse or external (Ford et al., 2015; Prpić et al., 2015). Another consideration is whether to use paid or unpaid crowdsourcing. In unpaid crowdsourcing, recruiting participants can be more challenging and delivering the task more time demanding (Borromeo \& Toyama, 2016). Special attention is required to choose a task that is realistic and solvable and can be defined and decomposed (Ford et al., 2015; Lüttgens et al., 2014). Last, focusing on one project at a time and creating a preliminary baseline for the crowd to work on have also been considered as success factors (Stol et al., 2019; Y. Tran et al., 2016; Zahay et al., 2018; H. Zhu et al., 2014).

Designing the call for participation and orchestrating the activity: Following planning, a project announces an open call for participation. A precise description with timeline, requirements and expected goal makes it easy for an individual to assess whether they are interested and suitable for the project (Bush \& Balven, 2018; Girdauskiene et al., 2015; Niu et al., 2019; Tokarchuk et al., 2012). At the same time, incentives should be realistic and IP policy needs to be stated clearly to indicate that the participants' effort will be valued and not misused (Franke et al., 2013; Hanine \& Steils, 2019; Zogaj et al., 2014). Last, task instructions need to reflect the nature of the expected solution and how it balances the specifity of the outcome e.g. feasibility over creativity (Steils \& Hanine, 2016).

Running a crowdsourcing activity is a multidimensional mission. Selecting participants and assigning the tasks, if needed, can be either based on self-selection, on a qualification test or on experts' evaluation of the participants' personality, skills and experience (Dissanayake et al., 2015; Niu et al., 2019; Stol et al., 2019; Y. Tran et al., 2016). In addition, recognition as an acknowledgement, reward or social approbation honours participants' effort and motivates them to do their best (Bush \& Balven, 2018; Hanine \& Steils, 2019; Schäfer et al., 2017). Effective communication combined with transparent regulations and procedures promote accountability and trust (Hanine \& Steils, 2019). Building trust safeguards against knowledge spill overs (Zogaj et al., 2014). Among the best practices are the ongoing monitoring of the process and allowing revisions (Ebel et al., 2016; Zogaj et al., 2014). Assigning employees of the organisation or crowd members as crowd leaders is also suggested (Ford et al., 2015; Franzoni \& Sauermann, 2014; Lüttgens et al., 2014). Crowd leaders resemble project managers. They help to facilitate the process and motivate the participants. Social facilitation and interaction can be helpful, especially in tasks that have a higher degree of interdependencies and crowd members need to be aware of other people's progress (Feyisetan \& Simperl, 2017; Ford et al., 2015; Franzoni \& Sauermann, 2014; Niu et al., 2019; Y. Tran et al., 2016).

Validating and integrating new knowledge: Validating or evaluating the results can be either an internal corporate process or carried out by the crowd community (Niu et al., 2019; Stol et al., 2019). Companies may evaluate the results manually, by assigning the work to employees or experts, or perform it automatically by using quality assurance tools (Niu et al., 2019; Stol et al., 2019). Another way is community evaluation, where the crowd performs validation by rating, voting or testing as in a peer-reviewed process, sometimes followed by a secondary validation from experts (Niu et al., 2019; Stol et al., 2019). Data validation is quite important not only to ensure the correctness or appropriability of a solution, but also the originality (Stol et al., 2019). Submitting "stolen" solutions can result in reputation-related consequences or IP rights disputes (Stol et al., 2019).

Sometimes solution seekers, overwhelmed by fears and a lack of experience, approach crowdsourcing with reservation and do not invest efficiently in the activity. Concerns about revealing technological or managerial knowledge or not reaching the expected outcome drive them to provide limited effort and stagnated communication, which hinders the knowledge creation process (Gruner \& Power, 2017; Hanine \& Steils, 2019; Lüttgens et al., 2014; Marjanovic et al., 2012). At the same time, established corporate power dynamics might create obstacles for incoming knowledge (Ford et al., 2015; Lüttgens et al., 2014; Marjanovic et al., 2012). In order to deal with the organisational inertia, managing the 
process and integrating the produced knowledge may require change management (Ford et al., 2015; Lüttgens et al., 2014; Marjanovic et al., 2012).

\subsubsection{Crowd}

The impact of crowdsourcing on the crowd: An analysis of published media revealed that most of the public attention is drawn to the benefits and challenges organisations have in crowdsourcing, while the benefits and challenges from the crowd's perspective have been neglected (Sheehan \& Pittman, 2019). There is indeed evidence that crowd participants are found to benefit for their personal development by engaging in the creation process through experiential and social learning (Steils \& Hanine, 2016). But even in the case of paid microtasking of unskilled work where the crowd participants do not interact at all with each other, they are found to carry the feeling of professional solidarity and community (Almaatouq et al., 2019; Schmidt \& Jettinghoff, 2016).

At the same time, certain elements might provoke negative feelings that undermine these benefits. Crowd participants are concerned about the use of their contribution and intellectual property rights, especially when there is no procedural transparency (Deng et al., 2016; Hanine \& Steils, 2019). Consequently, this creates insecurity on whether their effort will be misused (Deng et al., 2016; Hanine \& Steils, 2019). Research shows that, among all participants, trust and commitment in the process affect the behaviour of participants that are more dependent on the work of others (Shen et al., 2014). In general, there are four types of worker marginalisation: economic, where the participants feel that their effort is taken advantage of; policy, where they cannot make efficient use of the crowdsourcing opportunities; technology, where they cannot deal with the usability requirements; and competence marginalisation, in which their work does not contribute to their personal development and competitiveness (Deng et al., 2016).

\subsection{Motivation Factors}

How different types of motivations influence participation: Enabling the right motivations can help to increase participation, attract the most suitable individuals and maintain engagement. Thus, an important part of the literature has made an effort to shed light on identifying the motivation mechanisms that can enhance the benefits of crowdsourcing activities.

One major form of motivation is financial compensation. The presence of a monetary reward is indeed considered important for drawing high participation (Brabham, 2008; Chit et al., 2017; Deng et al., 2016; Girdauskiene et al., 2015; C. K. M. Lee et al., 2015). This importance appears especially compelling for the less motivated users (Liu et al., 2012; Ren et al., 2019). However, research shows that the increase of the reward amount does not increase the number of participations proportionally (Cappa, Rosso, et al., 2019; Stol et al., 2019). Individuals might perceive higher monetary rewards as an indicator of a difficulty or as time-demanding (Cappa, Rosso, et al., 2019; T. Tran \& Park, 2015). Nevertheless, the presence of the monetary reward itself was not found to outweigh the significance of non-monetary motivations (Cappa, Rosso, et al., 2019; Stol et al., 2019). Financial rewards have also been linked with the quality of contributions, for example with more innovative and radical ideas (C. K. M. Lee et al., 2015; Mack \& Landau, 2015). On the other hand, in microtasking, the accuracy of unpaid work is found to be similar to or even better than paid work (Borromeo \& Toyama, 2016).

Career-related motivations have been identified in the literature as factors that can attract more participants in the context of more skill-oriented crowdsourcing. Learning is valuable for professionals, investors or entrepreneurs, who want to become more experienced (Baumgardner et al., 2017; Estrin et al., 2018) Learning also motivates amateur participants who want to engage in a creative job and improve their technical, cognitive and business skills or prepare for a future career (Acar, 2019; Brabham, 2008, 2010; Budhathoki \& Haythornthwaite, 2013; Taylor \& Joshi, 2019). Nevertheless, participants motivated by learning were not found to submit more innovative solutions (Mack \& 
Landau, 2015). Peer recognition has also been found to increase participation, as it offers individuals personal satisfaction and helps to find new professional opportunities (Brabham, 2008; Budhathoki \& Haythornthwaite, 2013; Girdauskiene et al., 2015; C. K. M. Lee et al., 2015; Taylor \& Joshi, 2019). The flexible working conditions were identified as important motivators as they provide greater working autonomy and independence (Acar, 2019; Deng et al., 2016; C. K. M. Lee et al., 2015; Taylor \& Joshi, 2019). Learning, peer recognition and problem-solving motivations have been linked with appropriate submissions (Acar, 2019). In addition, motivation for autonomy is linked with innovativeness (C. K. M. Lee et al., 2015).

Individual factors always create a thirst for action, for example the need to satisfy a personal interest (Solemon \& Bakar, 2018). The satisfaction of accepting a problem-solving challenge is also mentioned as mobilising participation (Aitamurto \& Saldivar, 2017; Brabham, 2010; C. K. M. Lee et al., 2015; Taylor \& Joshi, 2019). Furthermore, participation itself can offer fulfilment or fun, even in cases where the individual believes that their contribution will not influence the result (Aitamurto \& Saldivar, 2017; Brabham, 2008; Chit et al., 2017; Tokarchuk et al., 2012). For this reason, a gamified crowdsourcing activity can increase participation and engagement, especially for the less-motivated users, as it makes the experience more delightful and entertaining (Feyisetan \& Simperl, 2017; Liu et al., 2012).

Social interaction and community membership were found to increase participation (Brabham, 2008, 2010; Budhathoki \& Haythornthwaite, 2013; Girdauskiene et al., 2015; Hajiamiri \& Korku, 2015). Moreover, in mobile crowdsourcing they are also connected with the most active participants (Budhathoki \& Haythornthwaite, 2013; Liu et al., 2012). Being a member of a community helps to understand it better, learn from others' perspectives and find support (Aitamurto, 2015; Aitamurto \& Saldivar, 2017; Hajiamiri \& Korku, 2015; Tokarchuk et al., 2012). Interestingly, the social dimension of crowdsourcing was found to be important even in paid microtasking, which is individual and there is no social learning taking place at all. Working with the presence of others has been found to improve the accuracy and engagement of workers (Feyisetan \& Simperl, 2017). On the other hand, in individual innovation-related activities there is the concern that social facilitation can reduce innovation outcomes by peer influence and the homogenisation of contributions (Felin et al., 2017).

Altruism can also mobilize participation (Aitamurto, 2015; Cappa, Rosso, et al., 2019; Girdauskiene et al., 2015, 2015; Solemon \& Bakar, 2018, 2018; Tokarchuk et al., 2012). The fulfilment of working for a higher purpose, the idea of improving the society or reducing a societal problem motivates individuals to contribute (Aitamurto \& Saldivar, 2017; Cappa, Oriani, et al., 2019; Girdauskiene et al., 2015). On the other hand, though, supporting a crowdfunding campaign with a social orientation does not seem to influence the funders' decision (Motylska-Kuzma, 2018). Altruism in the sense of supporting democratic means and egalitarian ways of working has also been identified by a study as an important driver (Aitamurto, 2015). Although altruism increases participation, it does not necessarily mobilise the individuals to provide appropriate contributions (Acar, 2019). The participation of individuals itself might satisfy their feeling of duty and they consequently feel that they do not need to put in additional effort (Acar, 2019).

Another determining set of motivation factors illustrated in the literature is the category of taskrelated factors. A clear-cut, realistic description with specific requirements and timeline are important to attract a high number of participants (Girdauskiene et al., 2015; Niu et al., 2019; Tokarchuk et al., 2012). In this way, individuals can better judge whether the task is suitable, feasible, interesting or enjoyable for them to participate in. Also, fair compensation, procedural transparency and sufficient communication make participants feel useful and valued and maintain their involvement throughout the activity (Deng et al., 2016; Shen et al., 2014). The feeling of being valued can be further enhanced by feedback, but in the case of paid microtasking the evidence is ambiguous. Expressing gratitude appears to have a positive influence, but performance feedback before fulfilling the task seems to demotivate workers from completing it (Straub et al., 2015). 
Maintaining the equilibrium of engagement: Crowdsourcing is based on an open-call, where the tasks are assigned based on crowd self-selection and motivation for the projects. However, it is essential to engage until the end and fulfil the task. Not all the motivations that mobilise the crowd to participate are strong factors for their long-term engagement and once the initial motivations are satisfied, the participants disengage (Acar, 2019; Aitamurto \& Saldivar, 2017). An efficient approach is to target the most suitable participants carefully, identify what motivates them most and establish an ongoing motivation system from the open call to the end of the project (Ren et al., 2019). This can help to maintain the high quality of contributions at each stage of crowdsourcing and also increase the participants by mobilising the less frequent contributors (Franzoni \& Sauermann, 2014). A crowdsourcing activity is an ongoing battle of trying to keep the equilibrium of engagement by strengthening the factors that empower the crowd and minimising those that provoke resentment (Deng et al., 2016).

\section{Future Research}

In this last section we outline a few potential areas for research in each of the key themes identified in the literature.

Performance: There exists a strong connection in the literature between innovation activities, organisational learning and organisational performance (García-Morales et al., 2012; Kuo, 2011; Migdadi, 2019). This might indicate that, apart from the completion of the project, firms might have gains that help them to perform better in the long run. Can companies that employ crowdsourcing improve their future organisational performance? Also crowdsourcing has been identified as an instrument for organisations to maximise knowledge search and increase their innovation performance (Afuah \& Tucci, 2012). In order to achieve sustainability, prior literature suggests that organisations need to find a balance between explorative and exploitative innovation. As such, an important research question may be to examine whether crowdsourcing can be used to achieve the aims of an ambidextrous organisation. Furthermore, crowdfunding has been mostly studied as a means to increase investment performance. There is a need to study further the underlined interactions between the fundraisers and the crowd when it comes to innovation facilitation and organisational and market performance. Moreover, network effects are a critical factor that helps to increase participation and to fulfil the goals of crowdsourcing for sales, investments and the strategic expansion of an organisation. Network effects may influence the process of attracting more funds, the marketing and strategic expansion of firms and the learning processes for the entrepreneurs and the investors. Network effects have not been systematically studied, though.

Innovation: Moving beyond individual characteristics and behaviours that affect idea generation for innovation and NPD, an understudied area is peer influence. High heterogeneity might create communication barriers and result in ineffective solutions; low heterogeneity might bring poor innovation results. How do the levels of peer heterogeneity in a team and in a crowdsourcing community influence the number of ideas and the innovation quality of ideas produced by teams and individuals? Peer interaction is a dimension of idea generation mainly in collaborative crowdsourcing but it can also play a role in individual submissions through secondary community interaction. On one hand, there is the concern about the homogenisation of ideas deriving from interaction (Felin et al., 2017). On the other hand there is an indication that certain levels of connectivity are helpful in producing innovations (Björk \& Magnusson, 2009). What are the underlined network effects in the idea generation process and how do they influence the result? How do different degrees of connectivity in combination with actor characteristics contribute to knowledge construction and to producing innovations? Practising crowdsourcing for innovation can be different for different types of organisations (Desyllas et al., 2018; Randhawa et al., 2019). What are the constraints and benefits for different types of organisations that employ crowdsourcing for innovation? How do their characteristics affect their available choices and their innovation performance in the short and long 
run? Finally, the nature of the innovation can offer an interest research direction. For example, crowdsourcing can be studied in relation to the radical and incremental innovation, early vs mature innovations etc.

Operations: Crowdsourcing is a digital model that can connect different stakeholders. While several scholars explored how to identify suitable participants for project crowdsourcing, the respective aspect of crowdfunding has been understudied (Baumgardner et al., 2017). This can help platforms to perform efficient matchmaking between entrepreneurs and investors. In this direction, since stakeholders might come from different cultural backgrounds, research could also explore how the local intermediate environment influences the online behaviour in a crowdsourcing project. How do the local resources of the actors and their perceptions of social and professional relationships determine the operational decisions and project success? Also, despite research attempting to classify platforms regarding the main functions and processes, there has not been any attempt to explore the organisations' and individuals' perceptions on usability and satisfaction. In addition, while a large part of the media coverage and literature so far deals with how to leverage the crowd skills for the organisational needs, little research has been invested in examining the benefits for the crowd participants. For example, the effect of learning on the crowd's personal and professional development has not been explored (Sheehan \& Pittman, 2019; Steils \& Hanine, 2016). Similarly, crowd challenges, such as dissatisfaction due to unmet expectations and perceived exploitation, also constitute an understudied area that is important to highlight for productivity but also for ethical reasons (Sheehan \& Pittman, 2019). Finally, what is the participants' perception on engaging during a crowdsourcing activity? What are the most common reasons they drop out?

Motivations: Current studies are aimed at identifying the motivations of individuals to participate in crowdsourcing, and some have attempted to link the motivations with the type of contributions. Research could also explore how to identify the individuals that repetitively provide inputs of high value and how to motivate them. In this way organisations and platforms could leverage their efficiency and potential in collaborating with them (Boons \& Stam, 2019; Zahay et al., 2018). Beyond attracting participants in the first place, ensuring engagement is important for reducing drop-out rates and for enhancing the quality of contributions. Thus, there is a need to discover ways of creating an ongoing motivation system. In addition, despite research exploring the crowd motivations to participate, the opposite, i.e. the organisations' motivations, has been understudied. Future research may study different types of companies to see how their drivers influence the crowdsourcing objectives and practices. Finally, research could examine why certain projects receive high attention while others do not manage to draw enough participants.

\section{References}

à Campo, S., Khan, V.-J., Papangelis, K., \& Markopoulos, P. (2019). Community heuristics for user interface evaluation of crowdsourcing platforms. Future Generation Computer Systems, 95, 775-789. https://doi.org/10.1016/j.future.2018.02.028

Acar, O. A. (2019). Motivations and solution appropriateness in crowdsourcing challenges for innovation. Research Policy, 48(8), 103716. https://doi.org/10.1016/j.respol.2018.11.010 
Afuah, A., \& Tucci, C. L. (2012). Crowdsourcing As a Solution to Distant Search. Academy of Management Review, 37(3), 355-375. https://doi.org/10.5465/amr.2010.0146

Agrawal, A., Catalini, C., \& Goldfarb, A. (2015). Crowdfunding: Geography, Social Networks, and the Timing of Investment Decisions. Journal of Economics \& Management Strategy, 24(2), 253274. https://doi.org/10.1111/jems.12093

Aitamurto, T. (2015). Motivation Factors in Crowdsourced Journalism: Social Impact, Social Change, and Peer Learning. International Journal of Communication, 9(0), 21.

Aitamurto, T., \& Saldivar, J. (2017). Motivating Participation in Crowdsourced Policymaking: The Interplay of Epistemic and Interactive Aspects. Proc. ACM Hum.-Comput. Interact., 1(CSCW), 18:1-18:22. https://doi.org/10.1145/3134653

Aizawa, A. (2003). An information-theoretic perspective of $\mathrm{tf}-\mathrm{idf}$ measures. Information Processing \& Management, 39(1), 45-65. https://doi.org/10.1016/So306-4573(02)ooo21-3

Alfiero, S., Secinaro, S., Tradori, V., Rainero, C., Indelicato, A., Venuti, F., \& Casalegno, C. (2014). Communication as the Basis for a Sustainable Crowdfunding: The Italian Case. International Journal of Humanities and Social Science.

Allen, B. J., Chandrasekaran, D., \& Basuroy, S. (2018). Design Crowdsourcing: The Impact on New Product Performance of Sourcing Design Solutions from the "Crowd." Journal of Marketing, 82(2), 106-123. https://doi.org/10.1509/jm.15.0481

Almaatouq, A., Krafft, P., Dunham, Y., Rand, D. G., \& Pentland, A. (2019). Turkers of the World Unite: Multilevel In-Group Bias Among Crowdworkers on Amazon Mechanical Turk. Social $\begin{array}{llll}\text { Psychological and Personality } & \text { Science, } & 1948550619837002 .\end{array}$ https://doi.org/10.1177/1948550619837002

Al-Rawi, A. (2017). News Organizations 2.0. Journalism Practice, 11(6), 705-720. https://doi.org/10.1080/17512786.2016.1195239

Assis Neto, F. R., \& Santos, C. A. S. (2018). Understanding crowdsourcing projects: A systematic review of tendencies, workflow, and quality management. Information Processing \& Management, 54(4), 490-506. https://doi.org/10.1016/j.ipm.2018.03.006

Baumgardner, T., Neufeld, C., Huang, P. C.-T., Sondhi, T., Carlos, F., \& Talha, M. A. (2017). Crowdfunding as a Fast-Expanding Market for the Creation of Capital and Shared Value. Thunderbird International Business Review, 59(1), 115-126. https://doi.org/10.1002/tie.21766 
Bayus, B. L. (2012). Crowdsourcing New Product Ideas Over Time: An Analysis of Dell's Ideastorm Community (SSRN Scholarly Paper ID 1979557). Social Science Research Network. https://papers.ssrn.com/abstract $=1979557$

Björk, J., \& Magnusson, M. (2009). Where Do Good Innovation Ideas Come From? Exploring the Influence of Network Connectivity on Innovation Idea Quality. Journal of Product Innovation Management, 26(6), 662-670. https://doi.org/10.1111/j.1540-5885.2009.00691.x

Boons, M., \& Stam, D. (2019). Crowdsourcing for innovation: How related and unrelated perspectives interact to increase creative performance. Research Policy, 48(7), 1758-1770. https://doi.org/10.1016/j.respol.2019.04.005

Borromeo, R. M., \& Toyama, M. (2016). An investigation of unpaid crowdsourcing. Human-Centric Computing and Information Sciences, 6(1), 11. https://doi.org/10.1186/s13673-016-0o68-z

Brabham, D. C. (2008). Moving the crowd at iStockphoto: The composition of the crowd and motivations for participation in a crowdsourcing application. First Monday, 13(6). https://firstmonday.org/ojs/index.php/fm/article/view/2159

Brabham, D. C. (2010). Moving the Crowd at Threadless. Information, Communication \& Society, 13(8), 1122-1145. https://doi.org/10.1080/13691181003624090

Brabham, D. C. (2012). The Myth of Amateur Crowds. Information, Communication \& Society, 15(3), 394-410. https://doi.org/10.1080/1369118X.2011.641991

Budhathoki, N. R., \& Haythornthwaite, C. (2013). Motivation for Open Collaboration: Crowd and Community Models and the Case of OpenStreetMap. American Behavioral Scientist, 57(5), 548-575. https://doi.org/10.1177/0002764212469364

Bush, J. T., \& Balven, R. M. (2018). Catering to the crowd: An HRM perspective on crowd worker engagement. Human Resource Management Review. https://doi.org/10.1016/j.hrmr.2018.10.003

Cappa, F., Oriani, R., Pinelli, M., \& De Massis, A. (2019). When does crowdsourcing benefit firm stock $\begin{array}{lllll}\text { market } & \text { performance? } & \text { Research } & \text { Policy, } & \text { 48(9), }\end{array}$ https://doi.org/10.1016/j.respol.2019.103825

Cappa, F., Rosso, F., \& Hayes, D. (2019). Monetary and Social Rewards for Crowdsourcing. Sustainability, 11(10), 2834. https://doi.org/10.339o/su11102834 
Chit, R., Habbal, S., Ahmad, R., \& Habbal, A. (2017). Interlinked Motivation Model to Use Mobile Crowdsourcing Platforms Among Low-Income Citizens. Pertanika Journal of Science and Technology, 25, 99-108.

Chiu, C.-M., Liang, T.-P., \& Turban, E. (2014). What can crowdsourcing do for decision support? Decision Support Systems, 65, 40-49. https://doi.org/10.1016/j.dss.2014.05.010

Davlembayeva, D., Papagiannidis, S., \& Alamanos, E. (2019). Mapping the economics, social and technological attributes of the sharing economy. Information Technology \& People, 33(3), 841-872. https://doi.org/10.1108/ITP-02-2018-0085

Deng, X., Joshi, K. D., \& Galliers, R. D. (2016). The Duality of Empowerment and Marginalization in Microtask Crowdsourcing: Giving Voice to the Less Powerful Through Value Sensitive Design. MIS Quarterly, 4O(2), 279-A19.

Desyllas, P., Miozzo, M., Lee, H., \& Miles, I. (2018). Capturing Value from Innovation in KnowledgeIntensive Business Service Firms: The Role of Competitive Strategy. British Journal of Management, 29(4), 769-795. https://doi.org/10.1111/1467-8551.12273

Dhanaraj, C., \& Parkhe, A. (2006). Orchestrating Innovation Networks. Academy of Management Review, 31(3), 659-669. https://doi.org/10.5465/amr.2006.21318923

Di Pietro, F., Prencipe, A., \& Majchrzak, A. (2018a). Crowd Equity Investors: An Underutilized Asset for Open Innovation in Startups. California Management Review, 6o(2), 43-70. https://doi.org/10.1177/ooo8125617738260

Di Pietro, F., Prencipe, A., \& Majchrzak, A. (2018b). Crowd Equity Investors: An Underutilized Asset for Open Innovation in Startups. California Management Review, 6o(2), 43-70. https://doi.org/10.1177/ooo812561773826o

Dissanayake, I., Zhang, J., \& Gu, B. (2015). Task Division for Team Success in Crowdsourcing Contests: Resource Allocation and Alignment Effects. Journal of Management Information Systems, 32(2), 8-39. https://doi.org/10.1080/o7421222.2015.1068604

Dushnitsky, G., Guerini, M., Piva, E., \& Rossi-Lamastra, C. (2016). Crowdfunding in Europe: Determinants of Platform Creation across Countries. California Management Review, 58(2), 44-71. https://doi.org/10.1525/cmr.2016.58.2.44

Ebel, P. A., Bretschneider, U., \& Leimeister, J. M. (2016). Can The Crowd Do The Job? Exploring The Effects Of Integrating Customers Into A Company'S Business Model Innovation. International Journal of Innovation Management (Ijim), 2O(o7), 1-24. 
Eiteneyer, N., Bendig, D., \& Brettel, M. (2019). Social capital and the digital crowd: Involving backers to promote new product innovativeness. Research Policy, 48(8), 103744. https://doi.org/10.1016/j.respol.2019.01.017

Elia, G., \& Margherita, A. (2018). Assessing the maturity of crowdventuring for corporate entrepreneurship. $\quad$ Business Horizons, $\quad 61(2), \quad$ 271-283. https://doi.org/10.1016/j.bushor.2017.11.008

Estellés-Arolas, E., Navarro-Giner, R., \& González-Ladrón-de-Guevara, F. (2015). Crowdsourcing Fundamentals: Definition and Typology. In F. J. Garrigos-Simon, I. Gil-Pechuán, \& S. EstellesMiguel (Eds.), Advances in Crowdsourcing (pp. 33-48). Springer International Publishing. https://doi.org/10.1007/978-3-319-18341-1_3

Estrin, S., Gozman, D., \& Khavul, S. (2018). The evolution and adoption of equity crowdfunding: Entrepreneur and investor entry into a new market. Small Business Economics, 51(2), 425439. https://doi.org/10.1007/s11187-018-0009-5

Felin, T., Lakhani, K. R., \& Tushman, M. L. (2017). Firms, crowds, and innovation. Strategic Organization, 15(2), 119-140. https://doi.org/10.1177/1476127017706610

Feller, J., Finnegan, P., Hayes, J., \& O’Reilly, P. (2012). ‘Orchestrating' sustainable crowdsourcing: A characterisation of solver brokerages. The Journal of Strategic Information Systems, 21(3), 216-232. https://doi.org/10.1016/j.jsis.2012.03.002

Feyisetan, O., \& Simperl, E. (2017). Social Incentives in Paid Collaborative Crowdsourcing. ACM Trans. Intell. Syst. Technol., 8(6), 73:1-73:31. https://doi.org/10.1145/3078852

Fink, A. (2005). Conducting Research Literature Reviews: From the Internet to Paper. SAGE.

Ford, R. C., Richard, B., \& Ciuchta, M. P. (2015). Crowdsourcing: A new way of employing nonemployees? $\quad$ Business $\quad$ Horizons, $\quad 58(4), \quad 377-388$. https://doi.org/10.1016/j.bushor.2015.03.003

Franke, N., Keinz, P., \& Klausberger, K. (2013). “Does This Sound Like a Fair Deal?”: Antecedents and Consequences of Fairness Expectations in the Individual's Decision to Participate in Firm Innovation. Organization Science, 24(5), 1495-1516. https://doi.org/10.1287/orsc.1120.0794

Franzoni, C., \& Sauermann, H. (2014). Crowd science: The organization of scientific research in open $\begin{array}{lllll}\text { collaborative } & \text { projects. } & \text { Research } & \text { Policy, } & \text { 43(1), }\end{array}$ https://doi.org/10.1016/j.respol.2013.07.005 
García-Morales, V. J., Jiménez-Barrionuevo, M. M., \& Gutiérrez-Gutiérrez, L. (2012). Transformational leadership influence on organizational performance through organizational learning and innovation. Journal of Business Research, 65(7), 1040-1050. https://doi.org/10.1016/j.jbusres.2011.03.005

Ghezzi, A., Gabelloni, D., Martini, A., \& Natalicchio, A. (2018). Crowdsourcing: A Review and Suggestions for Future Research. International Journal of Management Reviews, 20(2), 343363. https://doi.org/10.1111/ijmr.12135

Girdauskiene, L., Venckuviene, V., \& Savaneviciene, A. (2015). Crowdsourcing as a Key Method for Start - ups Overcoming Valley of Death. Mediterranean Journal of Social Sciences, 6(3), 795.

Gleasure, R., \& Feller, J. (2016). Emerging technologies and the democratisation of financial services: A metatriangulation of crowdfunding research. Information and Organization, 26(4), 101-115. https://doi.org/10.1016/j.infoandorg.2016.09.001

Gruner, R. L., \& Power, D. (2017). What's in a crowd? Exploring crowdsourced versus traditional customer participation in the innovation process. Journal of Marketing Management, 33(1314), 1060-1092. https://doi.org/10.1080/0267257X.2017.1325389

Hajiamiri, M., \& Korku, F. (2015). Perceived values of web-based collective design platforms from the perspective of industrial designers in reference to Quirky and OpenIDEO.

Hanine, S., \& Steils, N. (2019). Ideation contests: Crowd management and valorization to avoid negative feelings of participants. Creativity and Innovation Management, 28(4), 425-435. https://doi.org/10.1111/caim.12325

Hartt, C. M. (2018). What are business students taught about farming: Do textbooks paint a negative picture? The International Journal of Management Education, 16(2), 193-204. https://doi.org/10.1016/j.ijme.2018.02.004

Hervé, F., \& Schwienbacher, A. (2018). Crowdfunding and Innovation. Journal of Economic Surveys, 32(5), 1514-1530. https://doi.org/10.1111/joes.12274

Hong, Y., Hu, Y., \& Burtch, G. (2018). Embeddedness, Pro-Sociality, and Social Influence: Evidence from Online Crowdfunding. 35 .

Hossain, M. (2017). Crowdfunding: Motives, Definitions, Typology and Ethical Challenges. Entrepreneurship Research Journal, 7(2), 253-274. https://doi.org/10.1515/erj-2015-0045

Hossain, M., \& Kauranen, I. (2015). Crowdsourcing: A comprehensive literature review. Strategic Outsourcing: An International Journal. https://doi.org/10.1108/SO-12-2014-0029 
Howe, J. (2009). Crowdsourcing: Why the Power of the Crowd is Driving the Future of Business. Crown Business.

Iyer, R., Khwaja, A. I., Luttmer, E. F. P., \& Shue, K. (2015). Screening Peers Softly: Inferring the Quality of Small Borrowers. Management Science, 62(6), 1554-1577. https://doi.org/10.1287/mnsc.2015.2181

Julien, P.-A. (2007). A Theory of Local Entrepreneurship in the Knowledge Economy. Edward Elgar Publishing. https://ideas.repec.org/b/elg/eebook/128oo.html

Kang, L. L., Jiang, Q. Q., \& Tan, C. H. (2017). Remarkable advocates: An investigation of geographic distance and social capital for crowdfunding. Information \& Management, 54(3), 336-348. https://doi.org/10.1016/j.im.2016.09.001

Keongtae Kim, \& Viswanathan, S. (2019). The Experts in the Crowd: The Role of Experienced Investors in a Crowdfunding Market. MIS Quarterly, 43(2), 347-372. https://doi.org/10.25300/MISQ/2019/13758

Ketonen-Oksi, S., Kärkkäinen, H., \& Jussila, J. (2017). How can crowds be used in developing complex industrial products? An analysis of factors impacting the usefulness of crowdsourcing outcomes. International Journal of Business Innovation and Research, 14(4), 460-478. https://doi.org/10.1504/IJBIR.2017.087843

Kohler, T. (2015). Crowdsourcing-Based Business Models: How to Create and Capture Value. California Management Review, 57(4), 63-84. https://doi.org/10.1525/cmr.2015.57.4.63

Kohler, T. (2018). How to Scale Crowdsourcing Platforms. California Management Review, 6o(2), 98121. https://doi.org/10.1177/00o8125617738261

Krippendorff, K. (2004). Content Analysis: An Introduction to Its Methodology. Sage. https://books.google.com.hk/books?id=q65703M3C8cC

Kuo, T. (2011). How to improve organizational performance through learning and knowledge? International Journal of Manpower, 32(5/6), 581-603. https://doi.org/10.1108/01437721111158215

Lee, C. K. M., Chan, C. Y., Ho, S., Choy, K. L., \& Ip, W. H. (2015). Explore the feasibility of adopting crowdsourcing for innovative problem solving. Industrial Management \& Data Systems. https://doi.org/10.1108/IMDS-09-2014-0249 
Lee, Y. S., Lo, R., Chen, C. Y., Lin, P. C., \& Wang, J. C. (2015). News topics categorization using latent Dirichlet allocation and sparse representation classifier. 136-137. https://doi.org/10.1109/ICCE-TW.2015.7216819

Lehner, O. M. (2013). Crowdfunding social ventures: A model and research agenda. Venture Capital, 15(4), 289-311. https://doi.org/10.1080/13691066.2013.782624

Liu, Y., Lehdonvirta, V., Alexandrova, T., \& Nakajima, T. (2012). Drawing on mobile crowds via social media. Multimedia Systems, 18(1), 53-67. https://doi.org/10.1007/soo530-011-0242-o

Lüttgens, D., Pollok, P., Antons, D., \& Piller, F. (2014). Wisdom of the crowd and capabilities of a few: Internal success factors of crowdsourcing for innovation. Journal of Business Economics, 84(3), 339-374. https://doi.org/10.1007/s11573-014-0723-7

Mack, T., \& Landau, C. (2015). Submission quality in open innovation contests-An analysis of individual-level determinants of idea innovativeness. $R \& D$ Management, $O(0)$. https://doi.org/10.1111/radm.12345

Malhotra, A., \& Majchrzak, A. (2014). Managing Crowds in Innovation Challenges. California Management Review, 56(4), 103-123. https://doi.org/10.1525/cmr.2014.56.4.103

Marjanovic, S., Fry, C., \& Chataway, J. (2012). Crowdsourcing based business models: In search of evidence for innovation 2.o. Science and Public Policy, 39(3), 318-332. https://doi.org/10.1093/scipol/scsoo9

Migdadi, M. M. (2019). Organizational learning capability, innovation and organizational performance. European Journal of Innovation Management, ahead-of-print(ahead-of-print). https://doi.org/10.1108/EJIM-11-2018-0246

Mollick, E. (2016, April 21). The Unique Value of Crowdfunding Is Not Money-It's Community. Harvard Business Review. https://hbr.org/2016/04/the-unique-value-of-crowdfunding-isnot-money-its-community

Mollick, E., \& Robb, A. (2016). Democratizing Innovation and Capital Access: The Role of Crowdfunding. California Management Review, 58(2), 72-87. https://doi.org/10.1525/cmr.2016.58.2.72

Motylska-Kuzma, A. (2018). Crowdfunding and Sustainable Development. Sustainability, 10, 4650. https://doi.org/10.3390/su10124650 
Muller, A., Hutchins, N., \& Cardoso Pinto, M. (2012). Applying open innovation where your company needs it most. Strategy \& Leadership, 4O(2), 35-42. https://doi.org/10.1108/10878571211209332

Muthukumaraswamy, K. (2010). When the Media Meet Crowds of Wisdom. Journalism Practice, 4(1), 48-65. https://doi.org/10.1080/17512780903068874

Nishikawa, H., Schreier, M., Fuchs, C., \& Ogawa, S. (2017). The Value of Marketing Crowdsourced New Products as Such: Evidence from Two Randomized Field Experiments. Journal of Marketing Research, 54(4), 525-539. https://doi.org/10.1509/jmr.15.0244

Niu, X.-J., Qin, S.-F., Vines, J., Wong, R., \& Lu, H. (2019). Key Crowdsourcing Technologies for Product Design and Development. International Journal of Automation and Computing, 16(1), 1-15. https://doi.org/10.1007/s11633-018-1138-7

Nucciarelli, A., Li, F., Fernandes, K. J., Goumagias, N., Cabras, I., Devlin, S., Kudenko, D., \& Cowling, P. (2017). From value chains to technological platforms: The effects of crowdfunding in the digital game industry. Journal of Business Research, 78, 341-352. https://doi.org/10.1016/j.jbusres.2016.12.030

Okoli, C., \& Schabram, K. (2010). A Guide to Conducting a Systematic Literature Review of Information Systems Research. SSRN Electronic Journal, 1o. https://doi.org/10.2139/ssrn.1954824

O'Neil, M. (2010). Shirky and Sanger, or the costs of crowdsourcing. Journal of Science Communication, 9(1), Co4. https://doi.org/10.22323/2.09010304

Poetz, M. K., \& Schreier, M. (2012). The Value of Crowdsourcing: Can Users Really Compete with Professionals in Generating New Product Ideas? Journal of Product Innovation Management, 29(2), 245-256. https://doi.org/10.1111/j.1540-5885.2011.00893.x

Prpić, J., Shukla, P. P., Kietzmann, J. H., \& McCarthy, I. P. (2015). How to work a crowd: Developing crowd capital through crowdsourcing. Business Horizons, 58(1), 77-85. https://doi.org/10.1016/j.bushor.2014.09.005

Randhawa, K., Wilden, R., \& West, J. (2019). Crowdsourcing without profit: The role of the seeker in open social innovation. $R \& D \quad$ Management, $49(3), \quad 298-317$. https://doi.org/10.1111/radm.12357

Ren, J., Ozturk, P., \& Yeoh, W. (2019). Online Crowdsourcing Campaigns: Bottom-Up versus Top-Down Process Model. Journal of Computer Information Systems, 59(3), 266-276. https://doi.org/10.1080/08874417.2017.1344592 
Riffe, D. (2005). Analyzing media messages: Using quantitative content analysis in research (2nd ed..). Mahwah, N.J. : Lawrence Erlbaum.

Roma, P., Messeni Petruzzelli, A., \& Perrone, G. (2017). From the crowd to the market: The role of reward-based crowdfunding performance in attracting professional investors. Research Policy, 46(9), 1606-1628. https://doi.org/10.1016/j.respol.2017.07.012

Saxton, G. D., Oh, O., \& Kishore, R. (2013). Rules of Crowdsourcing: Models, Issues, and Systems of Control. Information Systems Management, $30(1), \quad 2-20$. https://doi.org/10.1080/10580530.2013.739883

Schäfer, S., Antons, D., Lüttgens, D., Piller, F., \& Salge, T. O. (2017). Talk to Your Crowd. ResearchTechnology Management, 6o(4), 33-42. https://doi.org/10.1080/08956308.2017.1325689

Schmidt, G. B., \& Jettinghoff, W. M. (2016). Using Amazon Mechanical Turk and other compensated crowdsourcing sites. Business Horizons, 59(4), 391-400. https://doi.org/10.1016/j.bushor.2016.02.004

Scholz, N. (2015). The relevance of crowdfunding: The impact on the innovation process of small entrepreneurial firms. Springer Gabler, Wiesbaden. https://doi.org/10.1007/978-3-65809837-7

Sheehan, K. B., \& Pittman, M. (2019). Straight from the Source? Media Framing of Creative Crowd Labor and Resultant Ethical Concerns. Journal of Business Ethics, 154(2), 575-585. https://doi.org/10.1007/s10551-017-3484-8

Shen, X.-L., Lee, M. K. O., \& Cheung, C. M. K. (2014). Exploring online social behavior in crowdsourcing communities: A relationship management perspective. Computers in Human Behavior, 40 , 144-151. https://doi.org/10.1016/j.chb.2014.08.006

Short, J. C., Broberg, J. C., Cogliser, C. C., \& Brigham, K. H. (2010). Construct Validation Using Computer-Aided Text Analysis (CATA): An Illustration Using Entrepreneurial Orientation. $\begin{array}{lll}\text { Organizational } & \text { Research } & \text { Methods, }\end{array}$ https://doi.org/10.1177/1094428109335949

Short, J. C., Ketchen, D. J., McKenny, A. F., Allison, T. H., \& Ireland, R. D. (2017). Research on Crowdfunding: Reviewing the (Very Recent) past and Celebrating the Present. Entrepreneurship Theory and Practice, 41(2), 149-160. https://doi.org/10.1111/etap.12270 
Solemon, B., \& Bakar, W. M. L. W. (2018). Factors Motivating the Public to Participate in Crowdsourcing of Crime Information. International Journal of Engineering and Technology(UAE), 7, 583-588. https://doi.org/10.14419/ijet.v7i4.35.22917

Sørensen, I. E. (2012). Crowdsourcing and outsourcing: The impact of online funding and distribution on the documentary film industry in the UK. Media, Culture \& Society, 34(6), 726-743. https://doi.org/10.1177/0163443712449499

Stanko, M. A., \& Henard, D. H. (2017). Toward a better understanding of crowdfunding, openness and the consequences for innovation. Research Policy, 46(4), 784-798. https://doi.org/10.1016/j.respol.2017.02.003

Stayton, J., \& Mangematin, V. (2019). Seed accelerators and the speed of new venture creation. The Journal of Technology Transfer, 44(4), 1163-1187. https://doi.org/10.1007/s10961-017-9646o

Steils, N., \& Hanine, S. (2016). Creative contests: Knowledge generation and underlying learning dynamics for idea generation. Journal of Marketing Management, 32(17-18), 1647-1669. https://doi.org/10.1080/0267257X.2016.1251956

Steils, N., \& Hanine, S. (2019). Recruiting valuable participants in online IDEA generation: The role of brief instructions. Journal of Business Research, 96, 14-25. https://doi.org/10.1016/j.jbusres.2018.10.038

Stol, K., Caglayan, B., \& Fitzgerald, B. (2019). Competition-Based Crowdsourcing Software Development: A Multi-Method Study from a Customer Perspective. IEEE Transactions on Software Engineering, 45(3), 237-260. https://doi.org/10.1109/TSE.2017.2774297

Straub, T., Gimpel, H., Teschner, F., \& Weinhardt, C. (2015). How (not) to Incent Crowd WorkersPayment Schemes and Feedback in Crowdsourcing. Business \& Information Systems Engineering, 57(3), 167-179.

Taylor, J., \& Joshi, K. D. (2019). Joining the crowd: The career anchors of information technology workers participating in crowdsourcing. Information Systems Journal, 29(3), 641-673. https://doi.org/10.1111/isj.12225

Terjesen, S., \& Patel, P. C. (2017). In Search of Process Innovations: The Role of Search Depth, Search Breadth, and the Industry Environment. Journal of Management, 43(5), 1421-1446. https://doi.org/10.1177/0149206315575710 
Thürridl, C., \& Kamleitner, B. (2016). What Goes around Comes Around? Rewards as Strategic Assets in Crowdfunding. California Management Review, 58(2), 88-110. https://doi.org/10.1525/cmr.2016.58.2.88

Tokarchuk, O., Cuel, R., \& Zamarian, M. (2012). Analyzing Crowd Labor and Designing Incentives for Humans in the Loop. IEEE Internet Computing, 16(5), 45-51. https://doi.org/10.1109/MIC.2012.66

Tran, T., \& Park, J. Y. (2015). A Quantitative Study of Influencing Factors on Crowd Participation in a Crowdsourcing Project for Consumer Product Design. Industrial Engineering and Management Systems, 14(4), 325-334. https://doi.org/10.7232/iems.2015.14.4.325

Tran, Y., Yonatany, M., \& Mahnke, V. (2016). Crowdsourced translation for rapid internationalization in cyberspace: A learning perspective. International Business Review, 25(2), 484-494. https://doi.org/10.1016/j.ibusrev.2015.08.001

Tranfield, D., Denyer, D., \& Smart, P. (2003). Towards a Methodology for Developing EvidenceInformed Management Knowledge by Means of Systematic Review. British Journal of Management, 14(3), 207-222. https://doi.org/10.1111/1467-8551.00375

Vismara, S. (2016). Equity retention and social network theory in equity crowdfunding. Small Business Economics, 46(4), 579-590. https://doi.org/10.1007/s11187-016-9710-4

Walthoff-Borm, X., Vanacker, T. R., \& Collewaert, V. (2018). Equity Crowdfunding, Shareholder Structures, and Firm Performance (SSRN Scholarly Paper ID 3259463). Social Science Research Network. https://doi.org/10.1111/corg.12259

Wang, W., Mahmood, A., Sismeiro, C., \& Vulkan, N. (2019). The evolution of equity crowdfunding: Insights from co-investments of angels and the crowd. Research Policy, 48(8), 103727. https://doi.org/10.1016/j.respol.2019.01.003

Wexler, M. N. (2011). Reconfiguring the sociology of the crowd: Exploring crowdsourcing. International Journal of Sociology and Social Policy, 31(1-2), 6-20. http://dx.doi.org.ezproxy.lb.polyu.edu.hk/10.1108/01443331111104779

Xu, Y., Ribeiro-Soriano, D. E., \& Gonzalez-Garcia, J. (2015). Crowdsourcing, innovation and firm performance. Management Decision, 53(6), 1158-1169. https://doi.org/10.1108/MD-o62014-0408 
Ye, H., \& Kankanhalli, A. (2013). Leveraging Crowdsourcing for Organizational Value Co-Creation. Communications of the Association for Information Systems, 33(1). https://doi.org/10.17705/1CAIS.03313

Yuan, S.-T. D., \& Hsieh, C.-F. (2018). An impactful crowdsourcing intermediary design-A case of a service imagery crowdsourcing system. Information Systems Frontiers, 2O(4), 841-862. https://doi.org/10.1007/s10796-016-9700-8

Zahay, D., Hajli, N., \& Sihi, D. (2018). Managerial perspectives on crowdsourcing in the new product development process. Industrial Marketing Management, $71, \quad 41-53$. https://doi.org/10.1016/j.indmarman.2017.11.002

Zhu, H., Djurjagina, K., \& Leker, J. (2014). Innovative behaviour types and their influence on individual crowdsourcing performances. International Journal of Innovation Management, 18(06), 1440015. https://doi.org/10.1142/S1363919614400155

Zhu, J. J., Li, S. Y., \& Andrews, M. (2017). Ideator Expertise and Cocreator Inputs in CrowdsourcingBased New Product Development. Journal of Product Innovation Management, 34(5), 598616. https://doi.org/10.1111/jpim.12400

Zogaj, S., Bretschneider, U., \& Leimeister, J. M. (2014). Managing Crowdsourced Software Testing: A Case Study Based Insight on the Challenges of a Crowdsourcing Intermediary (SSRN Scholarly Paper ID 2471711). Social Science Research Network. https://papers.ssrn.com/abstract=2471711 